\title{
Supporting Information: Ion Diffusion in Chemically Amplified Resists
}

\author{
Christopher M. Bottoms, ${ }^{\dagger}$ Tanguy Terlier, ${ }^{\ddagger}$ Gila E. Stein, ${ }^{*}{ }^{\dagger}$ and Manolis \\ Doxastakis $* \dagger$ \\ $\dagger$ Department of Chemical and Biomolecular Engineering, University of Tennessee, Knoxville, TN \\ 37996, USA \\ $\ddagger$ Shared Equipment Authority, Rice University, Houston, TX 77005, USA \\ E-mail: gstein4@utk.edu; edoxasta@utk.edu
}




\section{Figure List}

S1. Gel Permeation Chromatography

S2. Hydrogen Nuclear Magnetic Resonance Spectroscopy

S3. Molecular Dynamics Forcefield Parameters

S4. Solvent Removal from Films

S5. Atomic Force Microscopy

S6. Time-of-Flight Secondary Ion Mass Spectrometry Calibration

S7. Chain Dynamics and Monomeric Friction

S8. TOF-SIMS Profiles and Fits for P(HOST-tBA-St)

S9. TOF-SIMS Profiles and Fits for P(HOST-AA-St) 


\section{Gel Permeation Chromatography (GPC)}

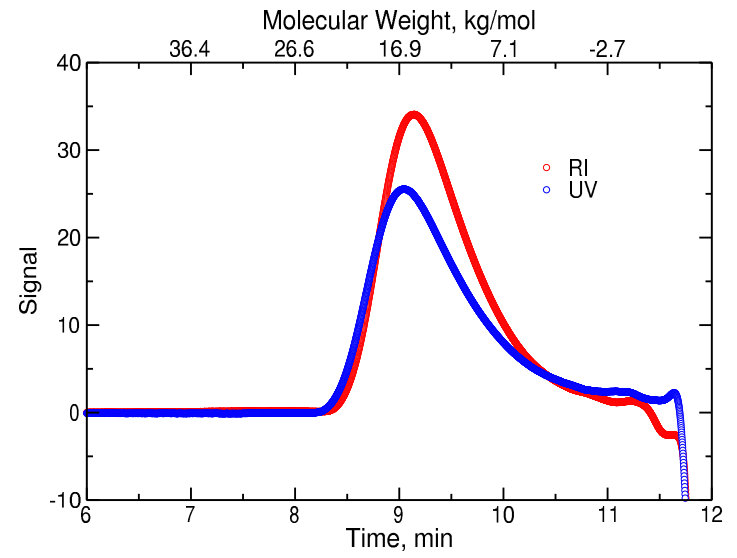

Figure S1: GPC trace of P(HOSt-tBA-St).

The molecular weight and dispersity of P(HOSt-tBA-St) were assessed using a Tosoh EcoSEC with a three column system of two Tosoh TSKgel SuperMultipore HZ-M $(4.6 \times 150 \mathrm{~mm}, 4 \mu \mathrm{m})$ columns and a TSKgel SuperMultipore HZ-M guard. Data were collected with both the RI and UV detectors at $40{ }^{\circ} \mathrm{C}$. THF was used as the mobile phase with a flow rate of $0.35 \mathrm{~mL} / \mathrm{min}$ at $40{ }^{\circ} \mathrm{C}$. Molecular weights were calculated relative to PS standards with a calibration range from 600 to $7,500,000 \mathrm{~g} / \mathrm{mol}$. The GPC trace data are summarized in Figure S1. For the RI detector, a weight-average molecular weight of $7.0 \mathrm{~kg} / \mathrm{mol}$ with a dispersity of 1.6 was determined. For the UV detector, a weight-average molecular weight of $6.6 \mathrm{~kg} / \mathrm{mol}$ with a dispersity of 1.7 was determined. 


\section{Hydrogen Nuclear Magnetic Resonance Spectroscopy $\left({ }^{1}\right.$ H NMR)}

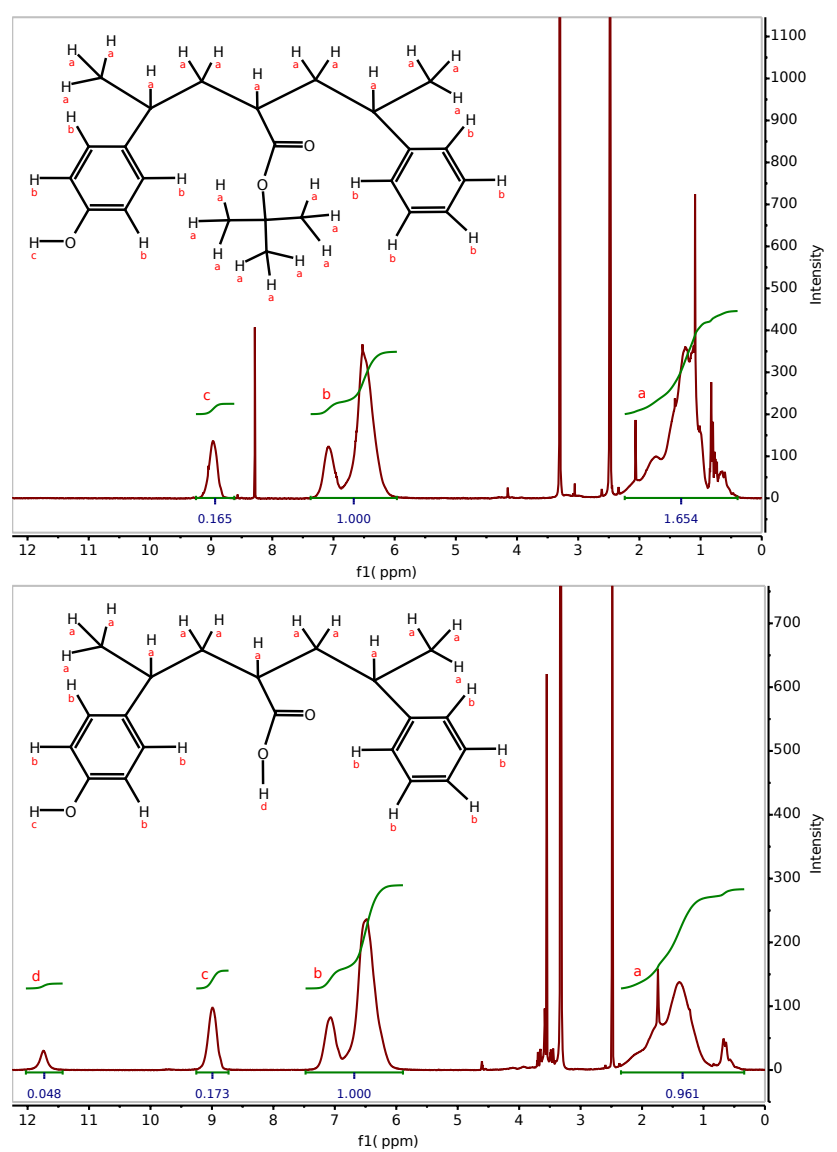

Figure S2: ${ }^{1} \mathrm{H}$ NMR Data of P(HOSt-tBA-St) (top) and P(HOSt-AA-St) (bottom)

${ }^{1} \mathrm{H}$ NMR spectras of $\mathrm{P}(\mathrm{HOSt}-\mathrm{tBA}-\mathrm{St})$ and chemically deprotected $\mathrm{P}(\mathrm{HOSt}-\mathrm{AA}-\mathrm{St})$ were obtained using a Varian VNMRS 500MHz spectrometer with a solvent of dimethyl sulfoxide-d 6 (DMSO$\left.\mathrm{d}_{6}\right)$. P(HOSt-tBA-St) composition, determined from the data in Figure S2a, was found to be 55\%$25 \%-20 \%$ by mole. Conversion of tBA to AA, determined from the data in Figure S2b, was determined to be $99 \%$ by tracking the loss of the strong peak at $1.09 \mathrm{ppm}$ which originates from the tert-butyl group in tBA. Trace contaminants of dimethyl sulfoxide $(2.50 \mathrm{ppm})$ and water (3.33 ppm), both present from DMSO- $\mathrm{d}_{6}$ absorbing and proton exchanging with water from the air, are present in each ${ }^{1} \mathrm{H}$ NMR spectra and trace contaminant of 1,4-dioxane (3.57 ppm) in P(HOSt-AA$\mathrm{St})$ is detectable, but weak. 


\section{Molecular Dynamics Forcefield Parameters}

The parameters for Lennard-Jones and Coulombic interactions as well as the intramolecular terms of the forcefield associated with parameters for bonds, angles, and dihedrals are summarized in Tables S1, S2, S3, and S4.

Table S1: Forcefield parameters for non-bonded interactions of polymers and penetrant in atomistic simulations.

\begin{tabular}{|c|c|c|c|c|}
\hline \multicolumn{5}{|c|}{ Non-bonded Interactions } \\
\hline Name and Structure & Atom/Group & $q_{i}(\mathrm{e})$ & $\sigma_{i i}(\AA)$ & $\varepsilon_{i i} / k_{b}(\mathrm{~K})$ \\
\hline \multirow[t]{4}{*}{ Na-TFL } & $\mathrm{CF}_{3}$ & -0.138 & 4.472 & 80.5 \\
\hline & $\mathrm{S}$ & 0.694 & 3.564 & 125.8 \\
\hline & $\mathrm{O}$ & -0.452 & 2.960 & 105.7 \\
\hline & $\mathrm{Na}$ & 0.800 & 3.300 & 1.4 \\
\hline \multirow[t]{7}{*}{ HOSt } & $\mathrm{CH}_{2}$ & 0.000 & 3.950 & 46.0 \\
\hline & $\mathrm{CH}$ & 0.000 & 4.650 & 10.0 \\
\hline & $\mathrm{CH}_{a r 1}$ & 0.000 & 3.700 & 30.0 \\
\hline & $\mathrm{CH}_{a r 2}$ & 0.000 & 3.695 & 50.5 \\
\hline & $\mathrm{CH}_{a r 3}$ & 0.265 & 4.333 & 10.0 \\
\hline & & -0.700 & 3.020 & 93.0 \\
\hline & $\mathrm{H}$ & 0.435 & 0.000 & 0.0 \\
\hline \multirow[t]{4}{*}{ St } & $\mathrm{CH}_{2}$ & 0.000 & 3.95 & 46.0 \\
\hline & $\mathrm{CH}$ & 0.000 & 4.65 & 10.0 \\
\hline & $\mathrm{CH}_{a r 1}$ & 0.000 & 3.700 & 30.0 \\
\hline & $\mathrm{CH}_{a r 2}$ & 0.000 & 3.695 & 50.5 \\
\hline \multirow[t]{6}{*}{ tBA } & $\mathrm{CH}_{2}$ & 0.000 & 3.95 & 46.0 \\
\hline & $\mathrm{CH}$ & 0.000 & 4.65 & 10.0 \\
\hline & $\mathrm{C}=(\mathrm{O})$ & 0.400 & 3.820 & 40.0 \\
\hline & $\mathrm{O}=(\mathrm{C})$ & -0.400 & 3.050 & 79.0 \\
\hline & $\mathrm{O}$ & -0.250 & 2.800 & 55.0 \\
\hline & $\mathrm{C}$ & 0.250 & 5.800 & 0.5 \\
\hline \multirow[t]{6}{*}{ AA } & $\mathrm{CH}_{2}$ & 0.000 & 3.95 & 46.0 \\
\hline & $\mathrm{CH}$ & 0.120 & 4.65 & 10.0 \\
\hline & $\mathrm{C}=(\mathrm{O})$ & 0.420 & 3.900 & 41.0 \\
\hline & $\mathrm{O}=(\mathrm{C})$ & -0.450 & 3.050 & 79.0 \\
\hline & $\mathrm{O}$ & -0.460 & 3.020 & 93.0 \\
\hline & $\mathrm{H}$ & 0.370 & 0.000 & 0.0 \\
\hline Chain Ends & $\mathrm{CH}_{3}$ & 0.000 & 3.750 & 98.0 \\
\hline
\end{tabular}


Table S2: United-Atom forcefield parameters for bond lengths of polymers and penetrant in atomistic simulations.

\begin{tabular}{|c|c|c|}
\hline \multicolumn{3}{|c|}{ Bond Lengths } \\
\hline Name & Bond & Length $(\AA)$ \\
\hline \multirow[t]{2}{*}{ TFL } & $\mathrm{CF}_{3}-\mathrm{S}$ & 2.400 \\
\hline & $\mathrm{O}-\mathrm{S}$ & 1.450 \\
\hline \multirow[t]{5}{*}{ HOSt } & $\mathrm{CH}_{2}-\mathrm{CH}$ & 1.540 \\
\hline & $\mathrm{CH}_{2}-\mathrm{C}_{a r}$ & 1.510 \\
\hline & $\mathrm{CH}_{a r}-\mathrm{CH}_{a r}$ & 1.400 \\
\hline & $\mathrm{C}-\mathrm{O}$ & 1.360 \\
\hline & $\mathrm{O}-\mathrm{H}$ & 0.945 \\
\hline \multirow[t]{3}{*}{ St } & $\mathrm{CH}_{2}-\mathrm{CH}$ & 1.540 \\
\hline & $\mathrm{CH}_{2}-\mathrm{C}_{a r}$ & 1.510 \\
\hline & $\mathrm{CH}_{a r}-\mathrm{CH}_{a r}$ & 1.400 \\
\hline \multirow[t]{6}{*}{$\mathrm{tBA}$} & $\mathrm{CH}_{2}-\mathrm{CH}$ & 1.540 \\
\hline & $\mathrm{CH}_{2}-\mathrm{COO}$ & 1.520 \\
\hline & $\mathrm{CO}=\mathrm{O}$ & 1.200 \\
\hline & $\mathrm{CO}-\mathrm{O}$ & 1.344 \\
\hline & $\mathrm{O}-\mathrm{C}$ & 1.410 \\
\hline & $\mathrm{C}-\mathrm{CH}_{3}$ & 1.540 \\
\hline \multirow[t]{5}{*}{$\mathrm{AA}$} & $\mathrm{CH}_{2}-\mathrm{CH}$ & 1.540 \\
\hline & $\mathrm{CH}_{2}-\mathrm{COO}$ & 1.520 \\
\hline & $\mathrm{CO}=\mathrm{O}$ & 1.200 \\
\hline & $\mathrm{CO}-\mathrm{O}$ & 1.344 \\
\hline & $\mathrm{O}-\mathrm{H}$ & 0.970 \\
\hline
\end{tabular}


Table S3: United-Atom forcefield parameters for bond angles and bending constants of polymers and penetrant in atomistic simulations, where $\theta$ is the angle between atoms ijk.

\begin{tabular}{|c|c|c|c|}
\hline \multicolumn{4}{|c|}{$\begin{array}{l}\text { Bond Angles and Bending Constants } \\
\qquad V_{a}\left(\theta_{i j k}\right)=\frac{1}{2} k_{\theta}\left(\theta-\theta_{0}\right)^{2}\end{array}$} \\
\hline Name & Bend & $\theta_{0}\left(^{\circ}\right)$ & $k_{\theta}\left(\mathrm{kJmol}^{-1} \mathrm{rad}^{-2}\right)$ \\
\hline TFL & $\begin{array}{l}\mathrm{O}-\mathrm{S}-\mathrm{CF}_{3} \\
\mathrm{O}-\mathrm{S}-\mathrm{O}\end{array}$ & $\begin{array}{l}103.2 \\
114.6\end{array}$ & $\begin{array}{l}640.152 \\
624.253\end{array}$ \\
\hline HOSt & $\begin{array}{l}\mathrm{CH}_{i}-\mathrm{CH}-\mathrm{CH}_{j} \\
\mathrm{CH}_{i}-\mathrm{C}_{a r}-\mathrm{CH}_{a r} \\
\mathrm{C}_{a r}-\mathrm{CH}_{a r}-\mathrm{CH}_{a r} \\
\mathrm{CH}_{a r}-\mathrm{C}_{a r}-\mathrm{O} \\
\mathrm{C}_{a r}-\mathrm{O}-\mathrm{H}\end{array}$ & $\begin{array}{l}109.5 \\
109.5 \\
120.0 \\
122.5 \\
113.0\end{array}$ & $\begin{array}{l}520.000 \\
520.000 \\
1000.00 \\
335.000 \\
146.000\end{array}$ \\
\hline St & $\begin{array}{l}\mathrm{CH}_{i}-\mathrm{CH}-\mathrm{CH}_{j} \\
\mathrm{CH}_{i}-\mathrm{C}_{a r}-\mathrm{CH}_{a r} \\
\mathrm{C}_{a r}-\mathrm{CH}_{a r}-\mathrm{CH}_{a r}\end{array}$ & $\begin{array}{l}109.5 \\
109.5 \\
120.0\end{array}$ & $\begin{array}{l}520.000 \\
520.000 \\
1000.00\end{array}$ \\
\hline $\mathrm{tBA}$ & $\begin{array}{l}\mathrm{CH}_{i}-\mathrm{CH}-\mathrm{CH}_{j} \\
\mathrm{CH}_{2}-\mathrm{CH}-\mathrm{COO} \\
\mathrm{CH}-\mathrm{C}=\mathrm{O} \\
\mathrm{CH}-\mathrm{C}-\mathrm{O} \\
\mathrm{CO}-\mathrm{O}-\mathrm{C} \\
\mathrm{O}-\mathrm{C}-\mathrm{CH}_{3}\end{array}$ & $\begin{array}{l}109.5 \\
109.5 \\
126.0 \\
111.0 \\
115.0 \\
111.0\end{array}$ & $\begin{array}{l}520.000 \\
520.000 \\
335.000 \\
293.500 \\
520.000 \\
294.000\end{array}$ \\
\hline AA & $\begin{array}{l}\mathrm{CH}_{i}-\mathrm{CH}-\mathrm{CH}_{j} \\
\mathrm{CH}_{2}-\mathrm{CH}-\mathrm{COO} \\
\mathrm{CH}-\mathrm{C}=\mathrm{O} \\
\mathrm{CH}-\mathrm{C}-\mathrm{O} \\
\mathrm{CO}-\mathrm{O}-\mathrm{H}\end{array}$ & $\begin{array}{l}109.5 \\
109.5 \\
126.0 \\
111.0 \\
107.0\end{array}$ & $\begin{array}{l}520.000 \\
520.000 \\
335.000 \\
293.500 \\
146.000\end{array}$ \\
\hline
\end{tabular}


Table S4: Forcefield parameters and equations for dihedrals of polymers in atomistic simulations, where $\phi$ and $\xi$ are the angle between $i j k$ and $j k l$ planes of bonded atom sequence $i j k l$.

\begin{tabular}{|c|c|c|c|}
\hline \multicolumn{4}{|c|}{$\begin{array}{c}\text { Improper Dihedrals } \\
V_{i d}\left(\xi_{i j k l}\right)=\frac{1}{2} k_{\xi}\left(\xi-\xi_{0}\right)^{2}\end{array}$} \\
\hline Name & Dihedral & $\xi_{0}\left({ }^{\circ}\right)$ & $\begin{array}{l}\mathrm{k}_{\xi} \\
\left(\mathrm{kJ} / \mathrm{mol}^{*} \mathrm{rad}^{2}\right)\end{array}$ \\
\hline Pendant & $\mathrm{CH}-\mathrm{CH}_{2}-\mathrm{CH}-\mathrm{C}$ & 35.26 & 334.8 \\
\hline $\mathrm{HOSt} / \mathrm{St}$ & $\mathrm{CH}_{a r}-\mathrm{C}_{a r}-\mathrm{CH}_{a r}-\mathrm{CH}_{a r}$ & 0.0 & 167.4 \\
\hline AA & $\mathrm{CH}-\mathrm{CH}_{2}-\mathrm{CH}-\mathrm{O}$ & 0.0 & 167.4 \\
\hline AA & $\mathrm{CH}_{2}-\mathrm{CH}-\mathrm{O}-\mathrm{H}$ & 0.0 & 167.4 \\
\hline
\end{tabular}

\begin{tabular}{|l||l|l|l|l|}
\hline \multicolumn{5}{|c|}{ Proper Dihedrals } \\
$\qquad V_{d}\left(\phi_{i j k l}\right)=k_{\phi}\left(1+\cos \left(n \phi-\phi_{0}\right)\right)$ \\
\hline Name & Dihedral & $\phi_{0}\left({ }^{\circ}\right)$ & $\mathrm{k}_{\phi}(\mathrm{kJ} / \mathrm{mol})$ & multiplicity \\
\hline HOSt/St & $\mathrm{CH}_{n}-\mathrm{CH}-\mathrm{C}_{a r}-\mathrm{CH}_{a r}$ & 0.0 & 4.184 & 2 \\
\hline
\end{tabular}

\begin{tabular}{|l|l|l|l|l|l|}
\hline \multicolumn{7}{|c|}{ Ryckaert-Bellemans Dihedrals } \\
\multicolumn{7}{|c|}{$V_{r b}\left(\phi_{i j k l}\right)=\sum_{n=0}^{3} C_{n}\left(\cos \left(\phi-180^{\circ}\right)\right)^{n}$} \\
\hline Name & Dihedral & $\mathrm{c}_{0}(\mathrm{~kJ} / \mathrm{mol})$ & $\mathrm{c}_{1}(\mathrm{~kJ} / \mathrm{mol})$ & $\mathrm{c}_{2}(\mathrm{~kJ} / \mathrm{mol})$ & $\mathrm{c}_{3}(\mathrm{~kJ} / \mathrm{mol})$ \\
\hline Backbone & $\mathrm{CH}_{n}-\mathrm{CH}-\mathrm{CH}_{2}-\mathrm{CH}$ & 8.397 & 16.785 & 1.134 & -26.316 \\
\hline
\end{tabular}

\begin{tabular}{|l||l|l|l|l|l|}
\hline \multicolumn{5}{|c|}{ Fourier Dihedrals } \\
\multicolumn{6}{|c|}{$V_{F}\left(\phi_{i j k l}\right)=\frac{1}{2}\left[C_{1}(1+\cos (\phi))+C_{2}(1-\cos (2 \phi))+C_{3}(1+\cos (3 \phi))+C_{4}(1-\cos (4 \phi))\right]$} \\
\hline Name & Dihedral & $\mathrm{c}_{1}(\mathrm{~kJ} / \mathrm{mol})$ & $\mathrm{c}_{2}(\mathrm{~kJ} / \mathrm{mol})$ & $\mathrm{c}_{3}(\mathrm{~kJ} / \mathrm{mol})$ & $\mathrm{c}_{4}(\mathrm{~kJ} / \mathrm{mol})$ \\
\hline HOSt & $\mathrm{CH}_{a r}-\mathrm{C}_{a r}-\mathrm{O}-\mathrm{H}$ & 10.48 & 26.0 & 0.0 & 0.0 \\
tBA/AA & $\mathrm{CH}_{2}-\mathrm{CH}-\mathrm{C}=\mathrm{O}$ & 10.48 & 26.0 & 0.0 & 0.0 \\
tBA & $\mathrm{CH}_{-}-\mathrm{C}-\mathrm{O}-\mathrm{C}$ & 6.941 & 22.833 & 0.502 & 0.000 \\
tBA & $\mathrm{C}-\mathrm{O}-\mathrm{C}-\mathrm{CH}_{3}$ & -12.501 & 8.962 & -0.367 & 0.853 \\
\hline
\end{tabular}




\section{Solvent Removal from Films}
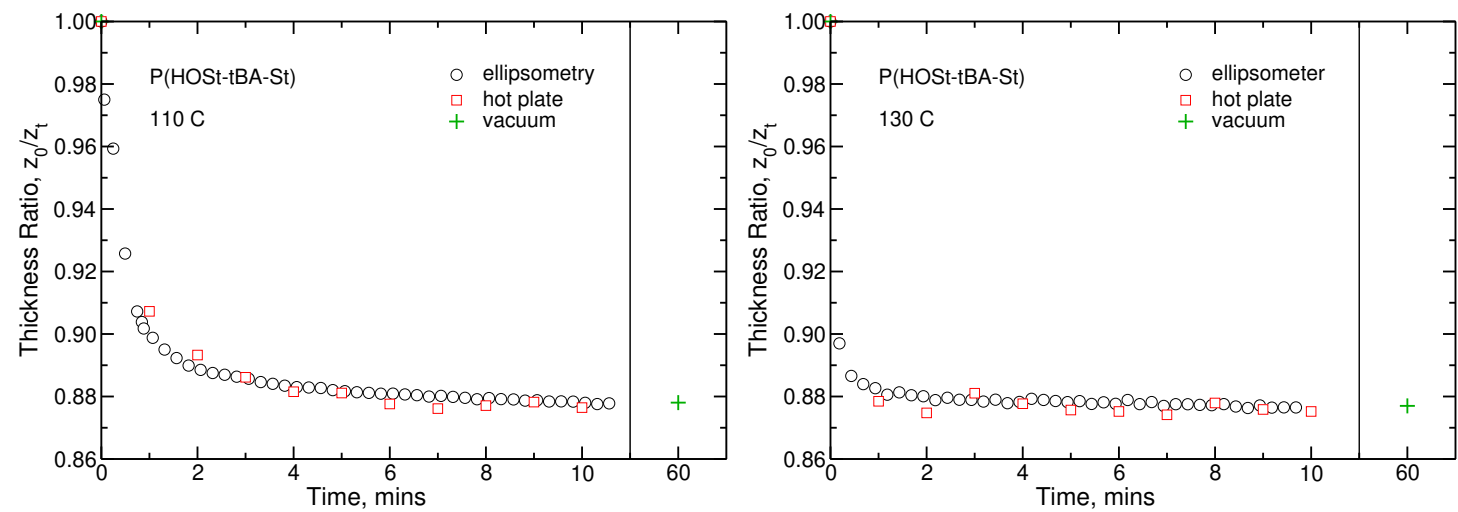

Figure S3: Normalized P(HOSt-tBA-St) thickness as a function of time for the three sample collection methods at baking temperatures of $110{ }^{\circ} \mathrm{C}$ (left) and $130{ }^{\circ} \mathrm{C}$ (right). Loss of thickness is attributed to the removal of PGMEA solvent.

All films used in these studies were prepared by spin-casting followed by baking to remove residual solvent. The films used for studies of reaction kinetics were baked at $130{ }^{\circ} \mathrm{C}$ for $4 \mathrm{~min}$. The films that were used to create the bilayer were baked at $110{ }^{\circ} \mathrm{C}$ for 6 mins, as we found that the lower temperature provides for a sharper interface and is still sufficient to remove PGMEA or ethyl acetate from the polymers. Data for PGMEA removal at 110 and $130{ }^{\circ} \mathrm{C}$ as a function of time are provided in Figure S3. (Ethyl acetate removal is faster than PGMEA removal due to its higher vapor pressure.) Data are reported as a normalized thickness (instantaneous thickness relative to initial thickness), as the removal of solvent can be observed through the shrinkage of the film. Three different techniques were used to track thickness as a function of temperature and time: (1) In-situ measurements using an ellipsometer equipped with heat cell; (2) Ex-situ approach where the sample was baked on a hotplate, cooled to room temperature, measured with ellipsometry, and then baked again; (3) Ex-situ approach where the sample was baked under vacuum for 60 min then measured with ellipsometry. The films were prepared from a solution containing $8 \mathrm{wt} \% \mathrm{P}(\mathrm{HOSt}-$ tBA-St) in PGMEA, which was spin-coated onto a silicon wafer at $2000 \mathrm{rpm}$ and produced a thickness of approximately $250 \mathrm{~nm}$ after solvent removal. After 6 minutes at $110{ }^{\circ} \mathrm{C}$ or 4 mins for $130{ }^{\circ} \mathrm{C}$, the normalized thickness by techniques 1 and 2 matched that of the vacuum-baked 
samples. Therefore, we believe that any remaining solvent in the films was negligible.

\section{Atomic Force Microscopy (AFM)}

AFM was performed using an Asylum MFP-3D Atomic Force Microscope. The topography and phase contrast were measured by scanning in tapping mode. The probes were silicon with a spring constant of approximately $9 \mathrm{~N} / \mathrm{m}$ and a resonance frequency of $115 \mathrm{kHz}$. The parameters used for image acquisition were $0.8 \mathrm{~Hz}$ scan frequency, $20 \mu \mathrm{m} \times 20 \mu \mathrm{m}$ scan size, and $256 \times 256$ image resolution. Raw AFM data were processed using the software provided by Asylum Instruments. First-order flattening was used to process both height and phase images. This eliminates any $\mathrm{z}$ offsets formed between scan lines by subtracting each point in the scan line with an average $\mathrm{z}$ value $(\mathrm{z}=$ phase or height). Solvent annealing in an atmosphere of ethyl acetate was used to remove large peaks and valleys (Figure S4b) in topography of the polymer films on the poly(dimethyl siloxane) after spincasting. This creates a smooth film interface (Figure S4c) for stamping onto the feeder layer. Final roughness of all interfaces was estimated to be $<5 \mathrm{~nm}$. 
a)
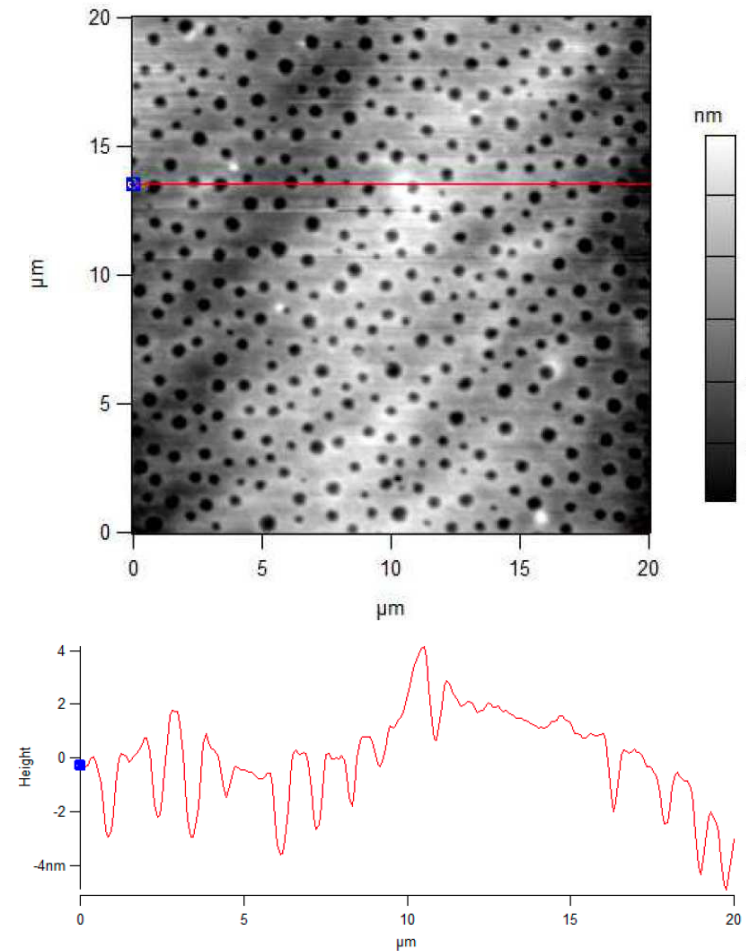

c)
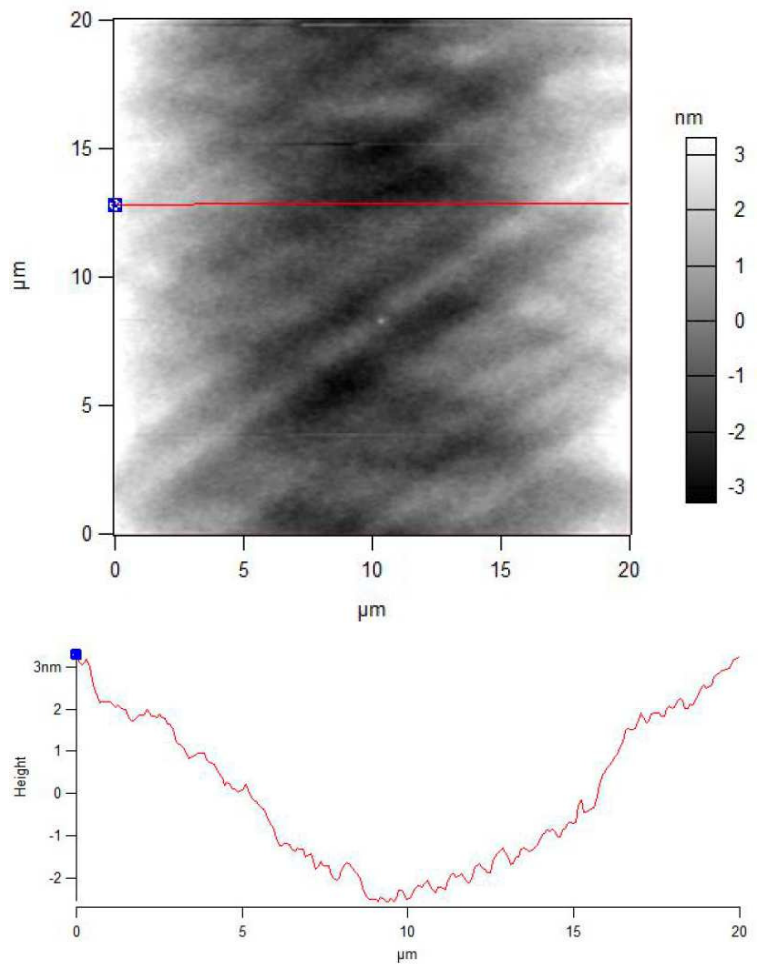

b)
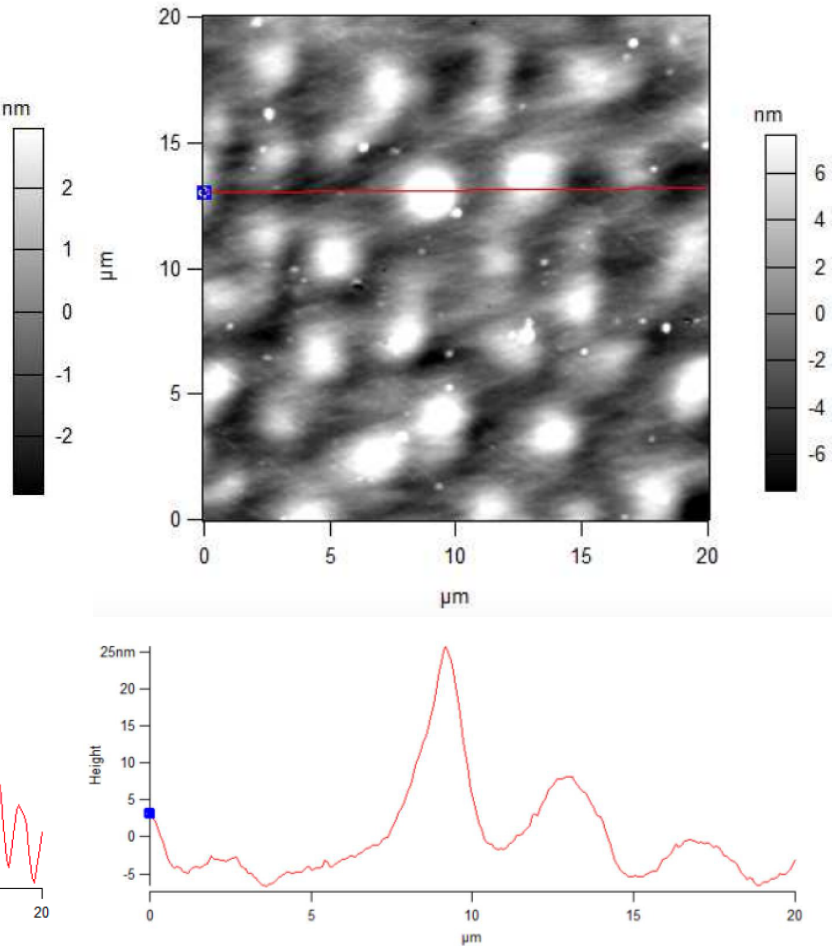

d)
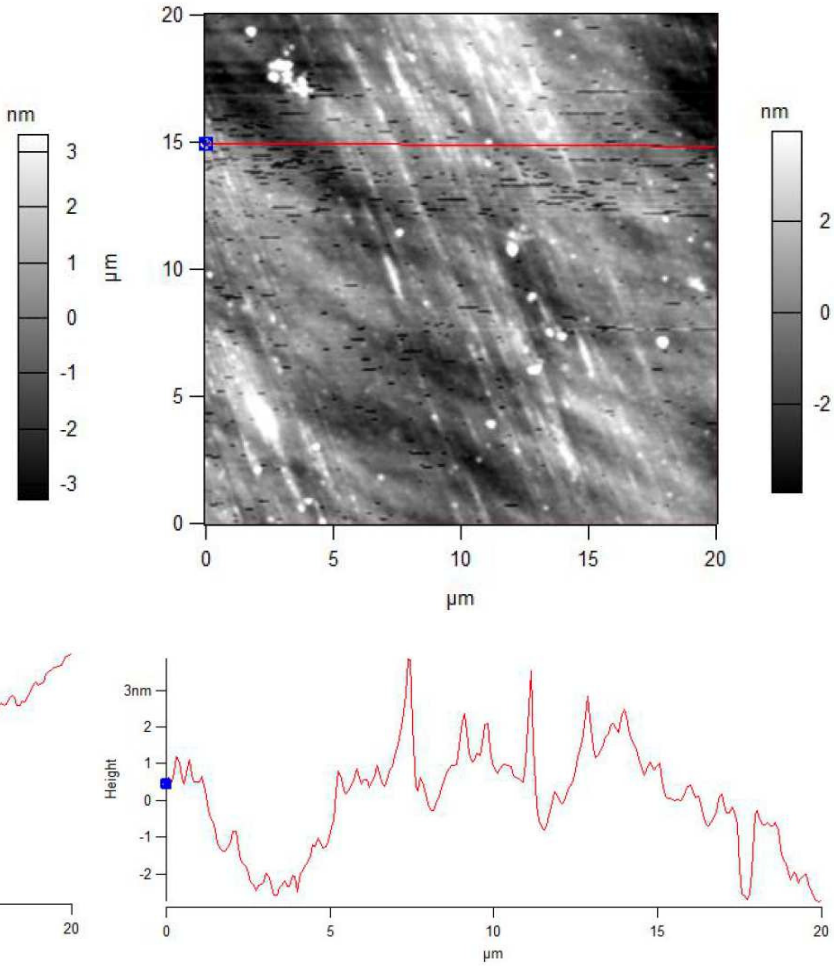

Figure S4: AFM images and cross-sectional profiles for analysis of roughness at interfaces during bilayer building. a) The PDMS stamp used for transferring the diffusion layer onto the feeder layer. b) $\mathrm{P}(\mathrm{HOSt}-\mathrm{tBA}-\mathrm{St})$ on the PDMS stamp before solvent annealing. c) P(HOSt-tBA-St) on the PDMS stamp after solvent annealing. d) The free surface of the bilayer after stamping. Images, except for the pre-solvent annealed film, show very low roughness on the order of a few nanometers. 


\section{Time-of-Flight Secondary Ion Mass Spectrometry Calibration}

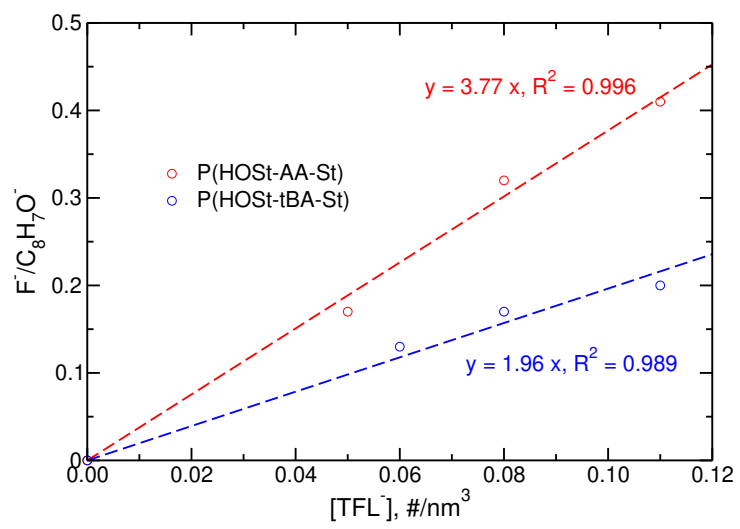

Figure S5: Counts of fluorine ions normalized to counts of the PHOSt fragment. Data show good linear agreement, in which the slope varies with chemistry, with the number density of triflate ions in the calibration samples.

Time-of-Flight Secondary Ion Mass Spectrometry (TOF-SIMS) data were calibrated through the use of the calibration curve provided in Figure S5. The calibration curve was obtained from films of $\mathrm{P}(\mathrm{HOSt}-\mathrm{tBA}-\mathrm{St})$ and $\mathrm{P}(\mathrm{HOSt}-\mathrm{AA}-\mathrm{St})$ with known concentrations of $\mathrm{Na}^{+} \mathrm{TFL}^{-}$and thicknesses of approximately $300 \mathrm{~nm}$. The relative ion counts for fluorine and an ionic fragment of PHOSt were determined from the bulk of the samples, at approximately $50 \mathrm{~nm}$ from the surface, and were found to have good linear agreement with the known number density of TFL- Every TOF-SIMS depth profile of bilayer samples was converted from relative ion counts to concentration using the respective curves for each chemistry. 


\section{Chain Dynamics and Monomeric Friction}
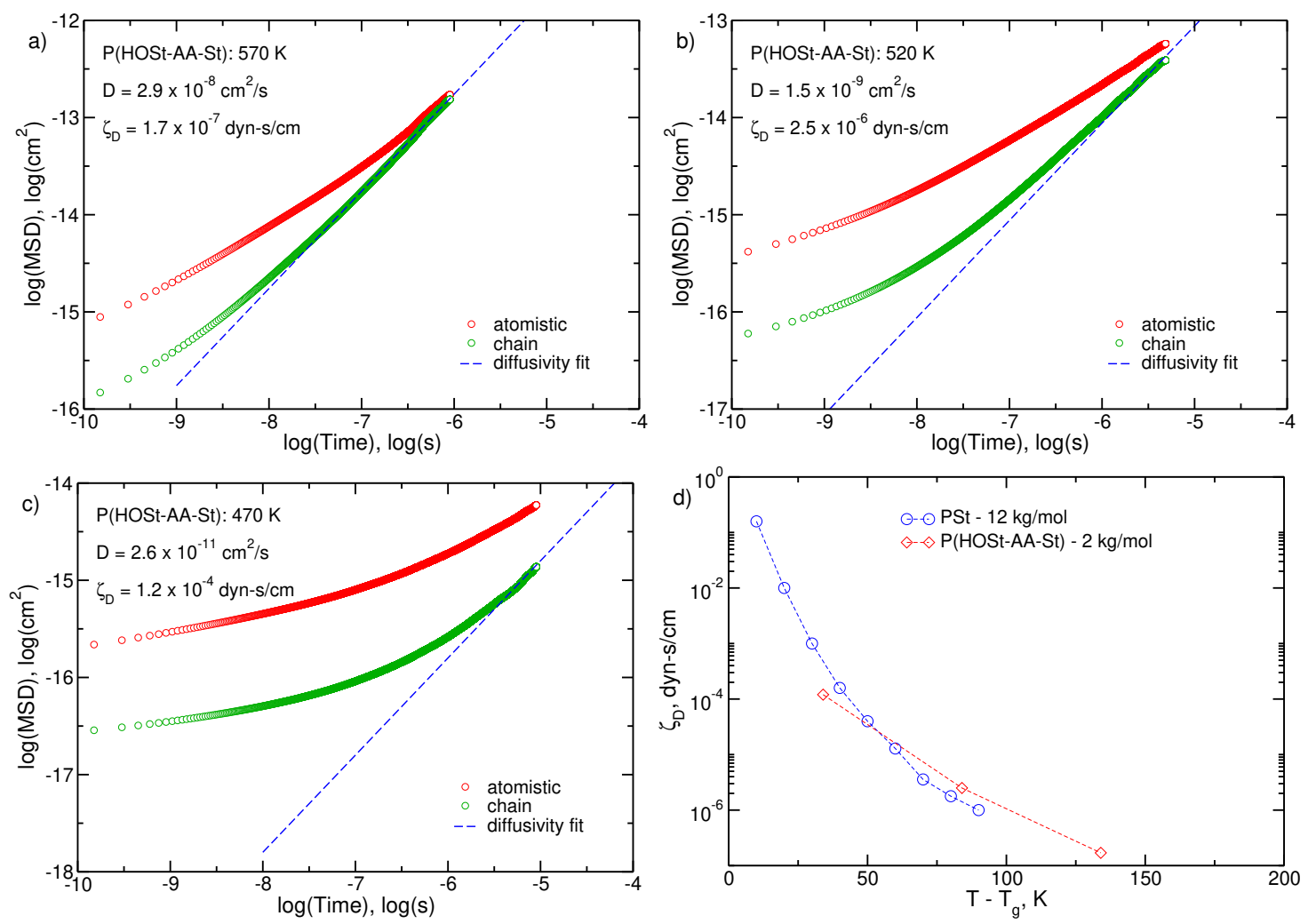

Figure S6: Atom and chain center of mass mean-square displacements of P(HOSt-AA-St) with linear fits to extract the chain center of mass diffusivity as a function of temperature (values shown on plots). Calculated monomeric friction coefficients are also provided (based on Eq: 1) and plotted as a function of temperature (relative to glass transition recorded by experiments). Monomeric friction coefficients for $12 \mathrm{~kg} / \mathrm{mol}$ polystyrene are also provided.

The polymer dynamics in the $0.11 \# / \mathrm{nm}^{3} \mathrm{Na}^{+} \mathrm{TFL}^{-} \mathrm{P}(\mathrm{HOSt}-\mathrm{AA}-\mathrm{St})$ system at 470,520 , and $570 \mathrm{~K}$ were analyzed through the mean-square displacement of polymer atoms and the center of mass of chains. Figure S6 shows that the trajectories at 570 and $520 \mathrm{~K}$ are sufficiently long to observe a convergence in the difference between the average displacements of individual polymer atoms and the displacements of the center of masses of polymer chains. At $470 \mathrm{~K}$ this has not occurred within the $10 \mu$ s simulations performed. Using the equation:

$$
\zeta_{D}=\frac{k_{B} T}{N D}
$$




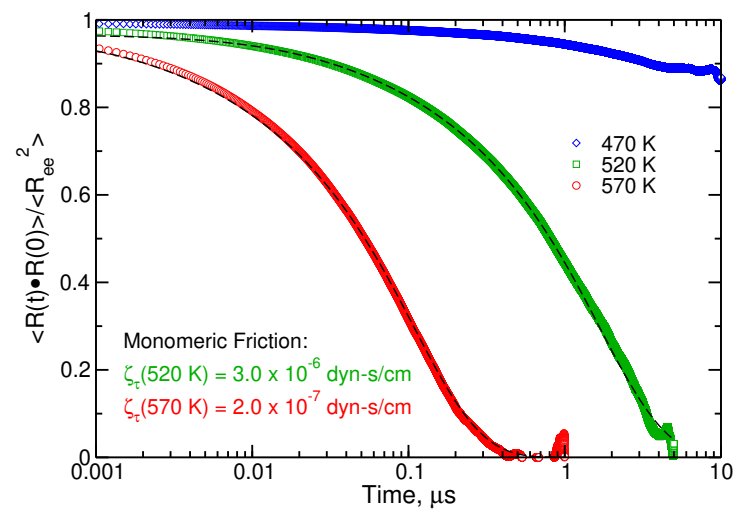

Figure S7: End-to-end vector autocorrelation, normalized by the mean square end-to-end distance, of $\mathrm{P}(\mathrm{HOSt}-\mathrm{AA}-\mathrm{St})$ as a function of temperature. Rouse fits for 520 and $570 \mathrm{~K}$ along with the extracted monomeric friction coefficients are provided.

where $k_{B}$ is the Boltzmann constant, $T$ is temperature, $N$ is the number of polymer repeat units, and $D$ is the diffusivity; the monomeric friction coefficient $\zeta_{D}$ was calculated as displayed in Figures S6a-c. The values extracted are also compared to experiment data of $12 \mathrm{~kg} / \mathrm{mol}$ polystyrene at all temperatures using the difference from the experimental glass transitions (for polystyrene and our system) as an independent variable. Eq. 1 presumes the applicability of the Rouse model. The corresponding relation for the end-to-end vector autocorrelation is:

$$
\langle R(t) \cdot R(0)\rangle=N b^{2} \sum_{p=1,3,5, \ldots} \frac{8}{\pi^{2} p^{2}} \exp \left(-\frac{t p^{2}}{\tau_{1}}\right)
$$

where $b$ is the statistical segment length, $p$ is the Rouse mode, $t$ is time, $\tau_{1}$ is the Rouse time (slowest relaxation mode), and $\langle R(t) \cdot R(0)\rangle$ is the end-to-end vector autocorrelation. Figure S7 provides the end-to-end vector autocorrelation of polymer chains and the corresponding Rouse description which appears satisfactory. Monomeric friction coefficients can also be extracted as:

$$
\zeta_{\tau}=3 \pi^{2} \frac{k_{B} T}{N<R_{e e}^{2}>} \tau_{1}
$$

where $\left\langle R_{e e}^{2}>\right.$ is the mean square end-to-end distance, and $\zeta_{\tau}$ is the monomeric friction coefficient. The values extracted at the two higher temperatures (where sufficient decorrelation was 
observed) are included in Figure S7 and are in good agreement with previous estimates supporting further the Rouse description. Note that relaxation of the end-to-end vector has not been reached within the time simulated at $470 \mathrm{~K}$. While we believe that this is not necessarily a requirement for sampling $\mathrm{Na}^{+} \mathrm{TFL}^{-}$diffusion (which decouples from polymer atomic displacements over the course of our simulation), $470 \mathrm{~K}$ was the lowest temperature we attempted to study with an initial configuration received from the $10 \mathrm{~K} / \mathrm{ns}$ quenching performed after relaxation at high temperatures.

\section{TOF-SIMS Profiles and Fits}

The diffusivity $D$ was calculated from the TOF-SIMS data (concentration of $\mathrm{Na}^{+} \mathrm{TFL}^{-}$versus distance) by integrating Fick's second law. This method of analysis involves (1) specifying the initial concentration profile (i.e., the initial condition at $t=0$ ); (2) integrating Fick's second law using the finite differences method for a proposed value of $D$; (3) convolving the theoretical profile with the experimental resolution function; and (4) optimizing $D$ to minimize the residuals. These steps are described in the following paragraphs. Note that each series of samples had its own "control" sample, which was an as-prepared bilayer. The control sample was used to calculate the experimental resolution function and determine the depth of the bilayer interface.

First, the initial $\mathrm{Na}^{+} \mathrm{TFL}^{-}$concentration (for $t=0$ ) as a function of depth into the film was modeled as a step function: the initial concentration of $\mathrm{Na}^{+} \mathrm{TFL}^{-}$is zero in the diffusion layer and is set to the experimental value in the feeder layer (i.e., $0.05 \# / \mathrm{nm}^{3}$ or $0.11 \# / \mathrm{nm}^{3}$ ). This starting configuration assumes that the bilayer interface is sharp, which is supported by the AFM data in Figure S4. Second, the time evolution of the depth-dependent $\mathrm{Na}^{+} \mathrm{TFL}^{-}$concentration was modeled by integrating Fick's second law (one-dimensional) using the finite differences method. This method was implemented with a spatial discretization of $1 \mathrm{~nm}$ and a time discretization that was adjusted according to the proposed diffusivity to maintain efficiency and stability. As examples, the time discretization was 0.06 seconds for a diffusivity of $1 \times 10^{-14} \mathrm{~cm}^{2} / \mathrm{s}$ and 60 seconds for a diffusivity of $1 \times 10^{-17} \mathrm{~cm}^{2} / \mathrm{s}$. The integration was performed from $t=0$ up to the total bake time 
$t_{f}$. Third, the modeled concentration profile (at $t_{f}$ ) was convolved with the experimental resolution function (a Gaussian) for comparison with measured concentration profiles. The experimental resolution function was determined from the control samples: The as-prepared bilayers had a sharp interface, but the measured profile in TOF-SIMS was broadened due to a combination of instrumental effects and the sputtering mechanisms of polymer films. As such, the control data were modeled by convolving the ideal step-function concentration profile with a Gaussian resolution function, where the standard deviation of the Gaussian was an adjustable parameter. The standard deviation was found to be roughly $20 \mathrm{~nm}$ for all samples. Fourth, the residuals for optimization were calculated by comparing the modeled concentration profile (post-convolution) with the experimental profile. Parameters for optimization were the diffusivity $D$ and the concentration of $\mathrm{Na}^{+} \mathrm{TFL}^{-}$in the feeder layer (bounded within $10 \%$ of the expected concentration, to account for small variations in the exact concentration from sample-to-sample). Data and corresponding fits are provided as a function of temperature, bake time, and $\mathrm{Na}^{+} \mathrm{TFL}^{-}$concentration for $\mathrm{P}(\mathrm{HOSt}-\mathrm{tBA}-$ $\mathrm{St})$ in Figure $\mathrm{S} 8$ and $\mathrm{P}(\mathrm{HOSt}-\mathrm{AA}-\mathrm{St})$ in Figure S9.

The uncertainty in experimental concentrations reflects a) errors in the measurement of TOFSIMS counts, which are orders of magnitude smaller than the reported counts; and b) errors stemming from the calibration curve that converts counts to concentration. Both uncertainties are smaller than the symbol size in Figure 8 and Figures S8 and S9. The uncertainty in the diffusivity values that were determined by optimizing Fick's model, following the steps described in the preceding paragraphs, could be examined by a) changing initial guesses in the optimization algorithm; b) resampling data based on errors in the experimental concentrations (bootstrapping); and c) removing a point and refitting (jacknife). All approaches would give a diffusivity value well within the size of the symbols in Figure 9. To illustrate this point, Figure 8 shows profiles generated with diffusivity values that are half and twice the optimized value, which approximately matches the range encompassed by the symbol size in Figure 9. The individual points are within this interval, so the symbol sizes are a conservative representation of errors in the extracted diffusivities that were extracted from Fick's law. 

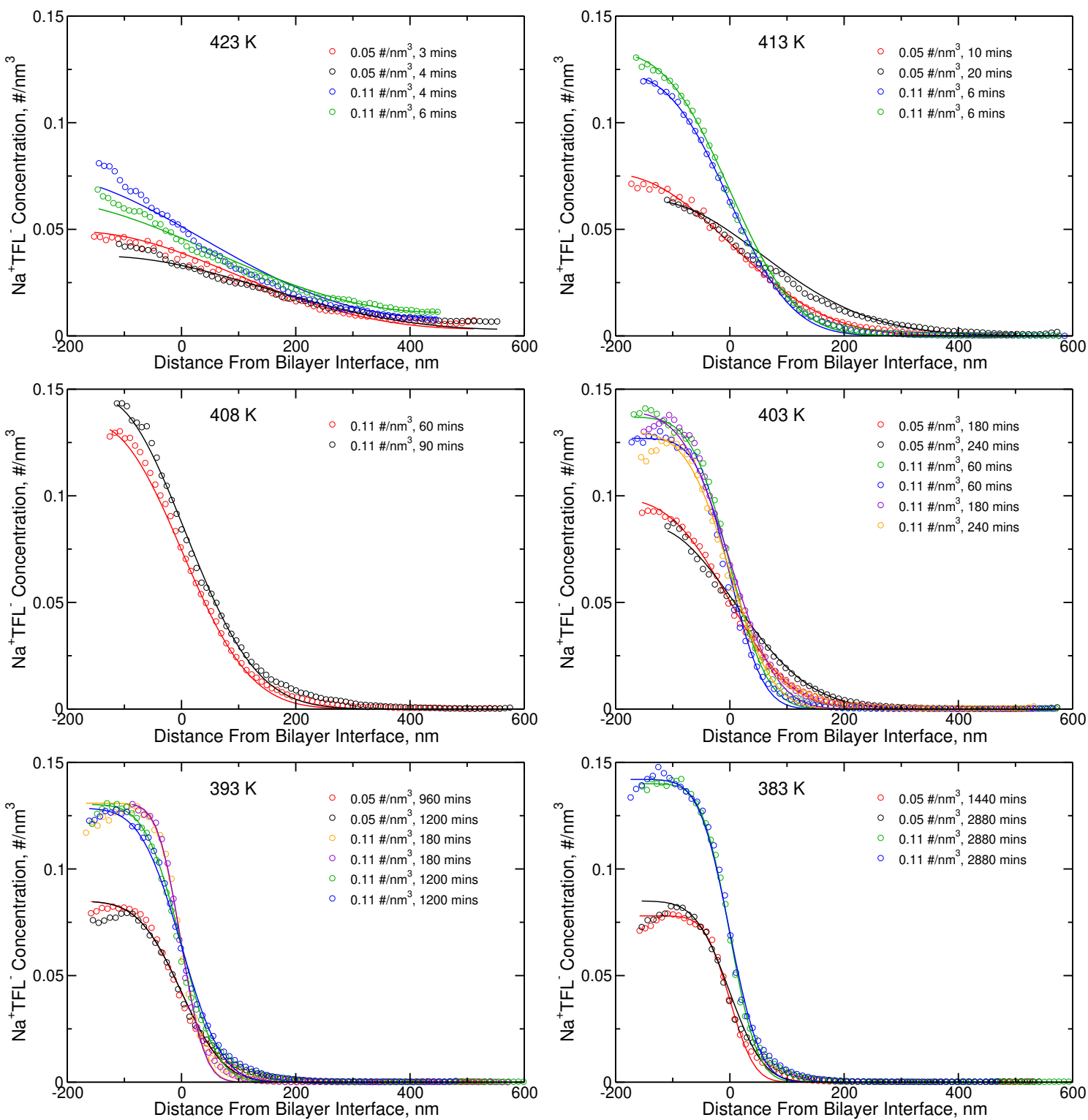

Figure S8: $\mathrm{Na}^{+} \mathrm{TFL}^{-}$concentration as a function of distance from the bilayer interface for $\mathrm{P}(\mathrm{HOSt}-$ tBA-St). The legend states the $\mathrm{Na}^{+} \mathrm{TFL}^{-}$concentration in the feeder layer as well as the baking time. The solid line is the optimized diffusion model. 

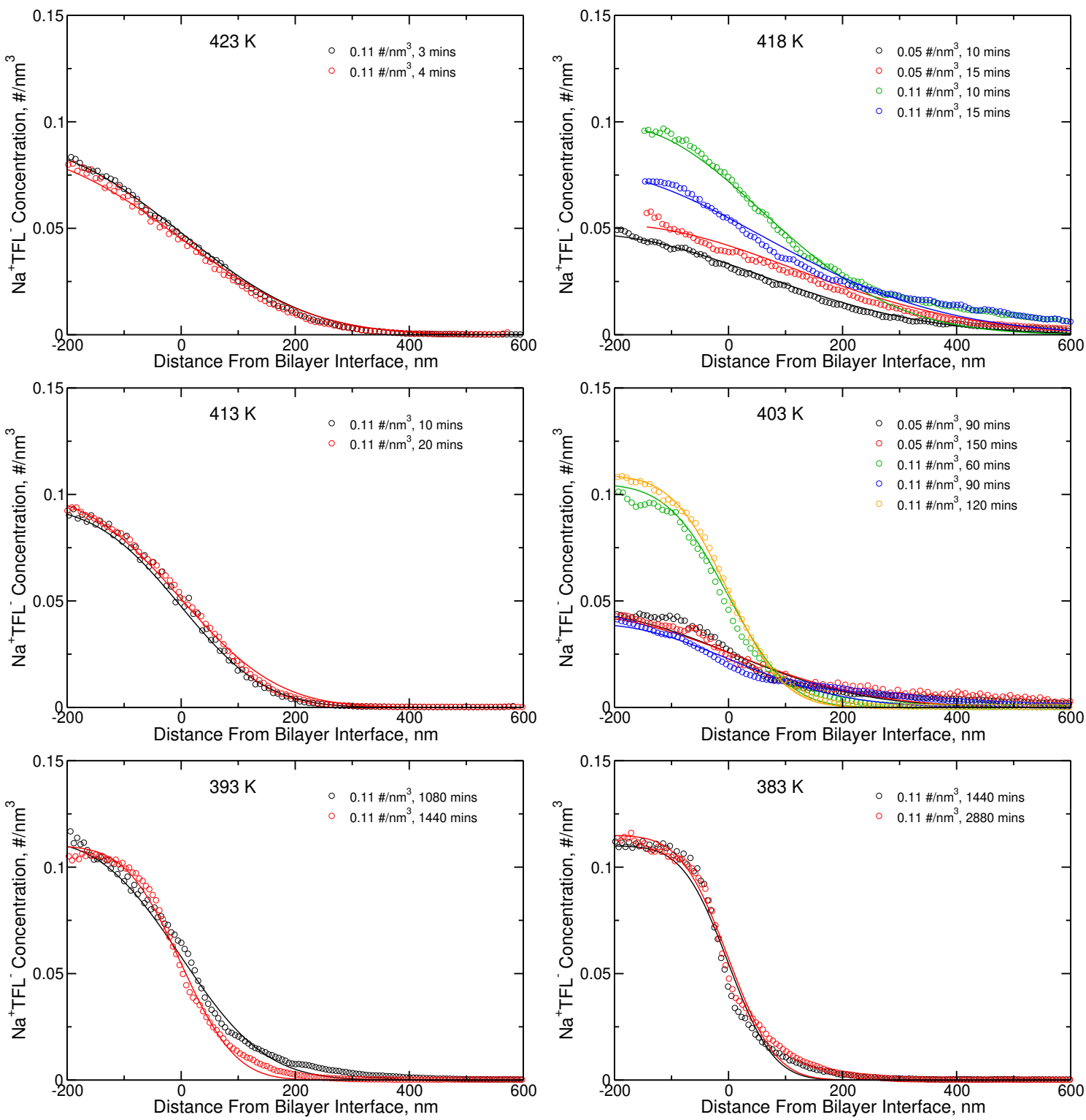

Figure $\mathrm{S} 9$ : $\mathrm{Na}^{+} \mathrm{TFL}^{-}$concentration as a function of distance from the bilayer interface for $\mathrm{P}(\mathrm{HOSt}-$ AA-St). The legend states the $\mathrm{Na}^{+} \mathrm{TFL}^{-}$concentration in the feeder layer as well as the baking time. The solid line is the optimized diffusion model. 